\title{
Cold tolerance of the Australian spur-throated locust, Austracris guttulosa
}

\author{
James D. Woodman* \\ Australian Plague Locust Commission, Australian Government Department of Agriculture, Fisheries and Forestry, GPO Box 858, Canberra 2601, Australia \\ Research School of Biology, College of Medicine, Biology and Environment, Australian National University, Canberra, ACT 0200, Australia
}

\section{A R T I C L E I N F O}

\section{Article history:}

Received 17 November 2011

Received in revised form 20 December 2011

Accepted 21 December 2011

Available online 29 December 2011

\section{Keywords:}

Insect

Low temperature

Cold hardiness

Freezing

Pre-freeze mortality

Acclimation

Feeding

Total body water content

\begin{abstract}
A B S T R A C T
The cold tolerance of overwintering adult Spur-throated locusts, Austracris guttulosa, was examined using measures of supercooling point relative to gender, environmental acclimation and feeding state as well as mortality for a range of sub-zero temperature exposure treatments. Freezing was lethal and supercooling points ranged from -6 to $-12.8^{\circ} \mathrm{C}$, but were statistically independent of fresh mass, body water content, acclimation, and/or gut content in fed and starved individuals. A significant interaction effect of gender and feeding status showed that the larger bodied females had decreased supercooling capacity with increased food material in the digestive tract. Post-freezing dissections revealed differences in the amount of freshly consumed and retained food material in the digestive tract between fed and starved individuals of each gender, which could explain this effect based on inoculation of ice crystallisation by food particles. Above supercooling temperatures, neither gender nor the rate of cooling had a significant effect on mortality. When cooled from $25^{\circ} \mathrm{C}$ at 0.1 or $0.5^{\circ} \mathrm{C} \mathrm{min}^{-1}$ to a range of experimental minimum temperatures held for $3 \mathrm{~h}$, survival was $\geqslant 74 \%$ to $-7{ }^{\circ} \mathrm{C}$, but declined sharply to $\leqslant 37 \%$ when cooled to $-8{ }^{\circ} \mathrm{C}$ or lower. Although the laboratory experiments reported here suggest that $A$. guttulosa is not freeze tolerant and unable to rapidly cold harden, exposure to typical cold and frosty nights that very rarely reach below $-8{ }^{\circ} \mathrm{C}$ as a night minimum in the field would be unlikely to cause mortality in the vast majority of overwintering aggregations.
\end{abstract}

Crown Copyright $\odot 2012$ Published by Elsevier Ltd. All rights reserved.

\section{Introduction}

Temperature is typically the most important abiotic factor affecting distribution and abundance of ectothermic animals (Chown and Nicholson, 2004). For insects that overwinter in environments that may be subject to sub-zero temperatures, a range of behavioural and physiological strategies may be employed to attempt to survive cold conditions (often with sub-optimal food and water availability) and complete their life cycle (Danks, 2007; Bale and Hayward, 2010). While small body size may permit utilisation of finely graded favourable microhabitat, any advantage must be considered relative to the increased climatic effects on hygrothermal regulation from high proportional body surface area (Wilmer, 1982; Danks, 2007). The cold tolerance of insects is highly variable among species, but nonetheless broadly consistent with macro-scale hemispheric variation in climate (Sinclair et al., 2003; Chown et al., 2004), and more specific measures such as total body water content, which generally varies between $40 \%$ and $90 \%$ of fresh weight for most species (Hadley, 1994).

\footnotetext{
* Present address: Australian Plague Locust Commission, Department of Agriculture, Fisheries and Forestry, GPO Box 858, Canberra 2601, Australia. Tel.: +61 2 62725075.

E-mail address: james.woodman@daff.gov.au
}

Lower lethal limits for insects able to survive sub-zero temperatures are typically preceded by either freeze avoidance by supercooling, or the ability to withstand and recover from internal body fluid crystallisation (Salt, 1961; Denlinger and Lee, 2010). While species with higher total body water are generally more susceptible to cold injury at low temperature, individual responses can be strongly dependent on a range of factors including life-stage, acclimation and metabolic state. For example, evacuation of gut contents and voluntary dehydration may be employed to remove ice nucleators and lower freezing potential in desiccation resistant species (e.g. Krunic and Radovic, 1974; Holmstrup and Sømme, 1998; review: Denlinger and Lee, 2010). Furthermore, low temperatures may induce an increase in low molecular weight compounds (e.g. polyols including glycerol, sorbitol) in the haemolymph which can act as anti-freeze and prevent ice formation from causing irreversible cellular damage (Lee and Denlinger, 1991; Bale, 2002; Elnitsky et al., 2008; Attapour and Moharramipour, 2009; Denlinger and Lee, 2010). Cold hardiness may depend on the rate of cooling (e.g. Worland, 2005), minimum temperature attained and the duration of exposure, whereby the extent of pre-freezing cold injury (e.g. loss of membrane function, see Kostal et al., 2004) and/or the supercooling point can vary relative to the effects (or lack thereof) of acclimation. Cold hardiness may be enhanced in many overwintering insect species by metabolic 
down-regulation and/or developmental arrest that may accompany the initiation of diapause or quiescence in response to declining day-length and temperature during autumn (Denlinger, 1986; Bale and Hayward, 2010).

The Australian spur-throated locust, Austracris guttulosa, is univoltine and occupies a broad distribution that in tropical and subtropical north-eastern Australia experiences a monsoonal climate with a short, wet season during summer and a prolonged dry season from April to September (Elder, 1995). Nymphs typically hatch during autumn and complete development to a pre-reproductive adult stage that overwinters during the dry season (Farrow, 1977; Hunter, 1997). However, the range of environmental conditions experienced by $A$. guttulosa is increased by long-distance migration that often broadly extends the species distribution south into more temperate regions (Farrow, 1977; Casimir and Edge, 1979). Long-term monitoring by the Australian Plague Locust Commission shows that $A$. guttulosa only rarely successfully reproduces further south than $31^{\circ} \mathrm{S}$ latitude (Farrow, 1977; Unpublished data, Australian Plague Locust Commission (APLC)) and commonly inhabits the central highlands region of Queensland where winter minimums may reach $-8^{\circ} \mathrm{C}$, or even colder with increasing altitude (Australian Government Bureau of Meteorology, 2011) (Fig. 1). Adult A. guttulosa may therefore experience wide thermal variability, but low temperature thresholds remain unknown despite potential value in forecasting the impacts of local environmental conditions on distribution and abundance. This study was designed to determine: (a) Can A. guttulosa resist freezing at subzero temperatures and is freezing fatal? (b) Does supercooling capacity vary with gender, environmental acclimation, and/or feeding state? (c) To what extent can A. guttulosa tolerate longer sub-zero temperature exposures preceded by different rates of temperature decline? (d) What are the likely implications of cold nights and frost on overwintering adult survival in the field?

\section{Materials and methods}

\subsection{Insects}

Young, pre-reproductive adult A. guttulosa were collected opportunistically in response to landholder and APLC swarm location reports in late May-August 2010 (estimated to have fledged during April 2010) from open grassland native pasture near Longreach $\left(23^{\circ} 36.894 \mathrm{~S}, 145^{\circ} 16.856 \mathrm{E}\right)$ in central Queensland, Australia for the supercooling experiments, and in July 2011 (estimated to have fledged during April 2011) from habitat along the Paroo River in the Wanaaring/Hungerford region $\left(29^{\circ} 32.645 \mathrm{~S}, 144^{\circ} 338 \mathrm{E}\right)$ in far northern New South Wales for the cold exposure mortality assays (Fig. 1). Climatically, the Longreach and Wanaaring/Hungerford regions experience wide annual temperature variation that typically extends from $-2{ }^{\circ} \mathrm{C}$ as a winter night minimum to in excess of $40{ }^{\circ} \mathrm{C}$ during daytime in summer. On average the areas are subject to 8-10 frost days per year distributed from June until September (Australian Government Bureau of Meteorology, 2011). Beyond September, night minimum temperatures steadily increase into summer and very rarely reach zero degrees. Young adults were selected for study based on a single generation per year that opportunistically migrates south into colder areas of southern New South Wales and Victoria and relies on successful overwintering as pre-reproductive diapause adults.

Incubation regimes for the supercooling experiments were selected to approximate late autumn/early winter and late spring/ early summer environmental conditions, whereby the former is associated with the initiation of overwintering diapause and the latter with uninhibited development (Elder, 1989, 1991, 1995). Therefore, locusts were divided by gender and then into two groups each to give male and female groups incubated at either a 12L:12D photoperiod at $25 \pm 0.5^{\circ} \mathrm{C}$ and $10 \pm 0.5{ }^{\circ} \mathrm{C}$ (similar to field

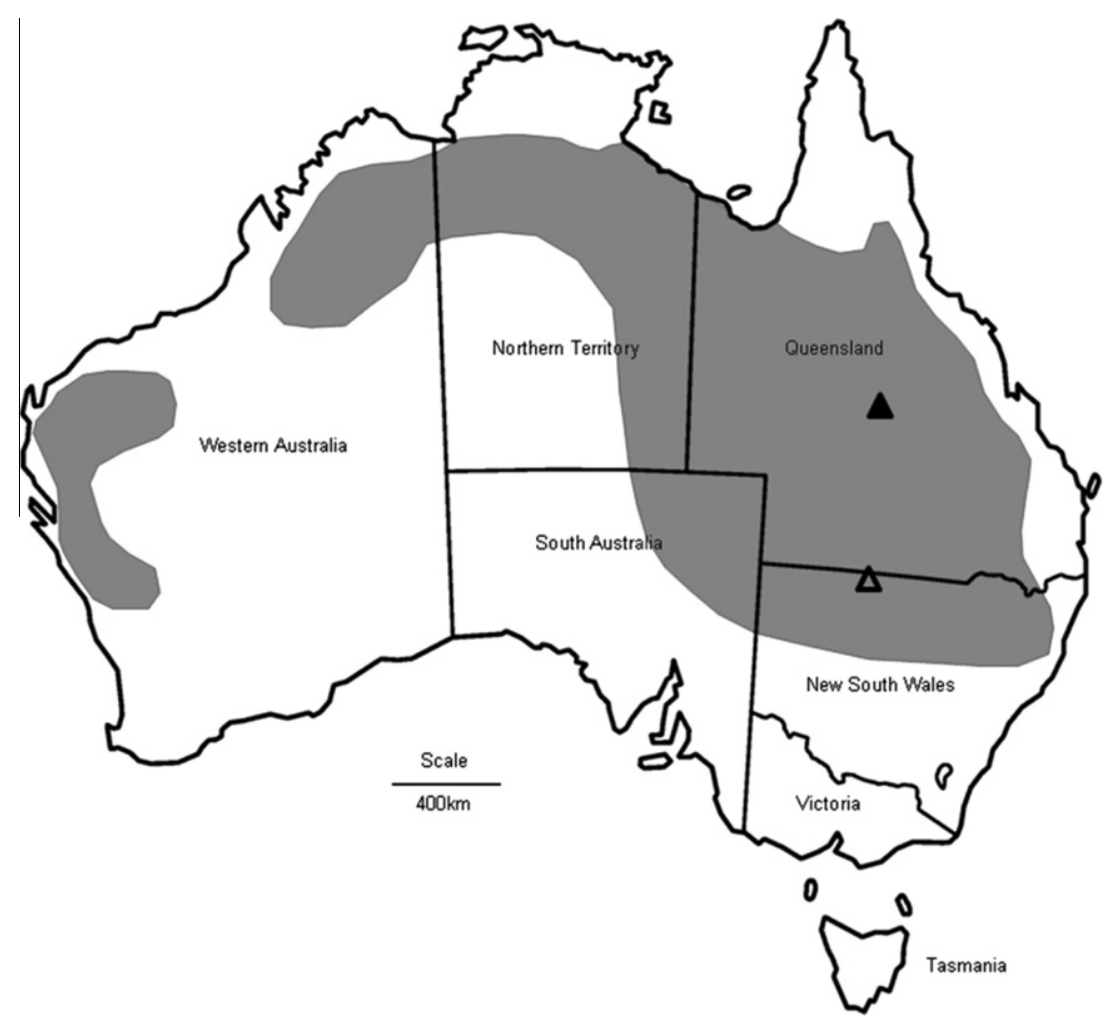

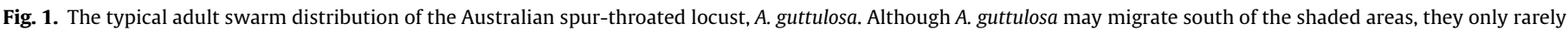

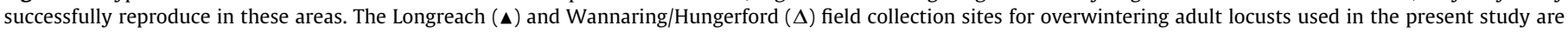
shown. 


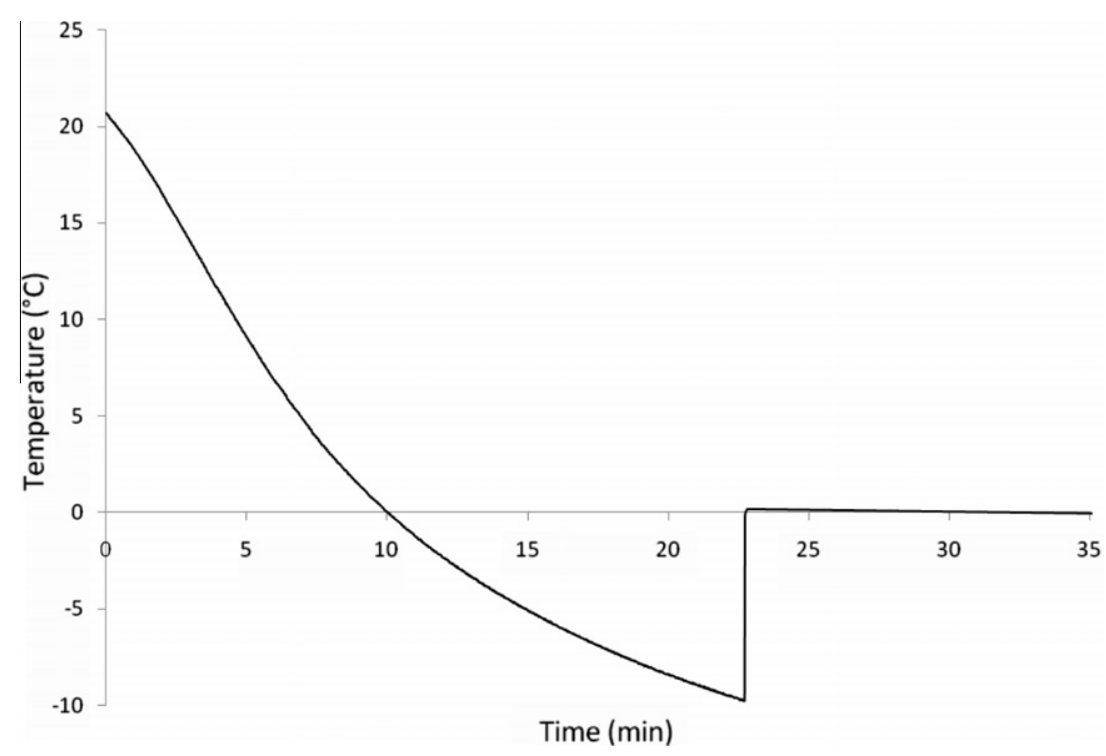

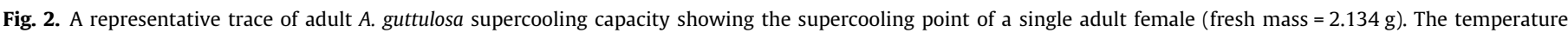

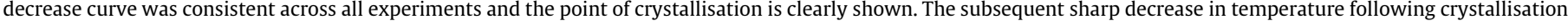
transition typically occurred after 10-15 min (dependent on body size) indicating the progression of freezing (not shown).

conditions at the time of collection and diapause initiation), or a 14L:10D photoperiod at $35 \pm 0.5^{\circ} \mathrm{C}$ and $20 \pm 0.5^{\circ} \mathrm{C}$ (uninhibited development) for 7-10 days before use respectively (TRIL 250-1SD, Thermoline Scientific, Australia). For the cold exposure mortality assays, locusts were divided by gender, but incubated only at 12L:12D photoperiod at $25 \pm 0.5^{\circ} \mathrm{C}$ and $10 \pm 0.5^{\circ} \mathrm{C}$. Locusts were contained in large plastic insect cages with aluminium mesh lids. All locusts were checked and cages cleaned daily to ensure adequate food supply and the prompt removal of frass and any dead individuals. Wheat seedlings grown in shallow aluminium trays and a moistened paper towel for water were provided to the locusts ad libitum. For starved treatments as part of the supercooling experiments, food was withheld for $48-72 \mathrm{~h}$ before locusts were used.

\subsection{Nymphal mass and total body water content}

Starved and fed locusts ( $n=11-16$ per group per sex) were weighed (sensitivity $0.1 \mathrm{mg}$, AB104-S, Mettler-Toledo, USA) and transferred live to individual, plastic specimen jars with perforated lids before being placed into a drying oven (TO-152F, Thermoline Scientific, Australia) at $90{ }^{\circ} \mathrm{C}$ for $48 \mathrm{~h}$ to achieve constant mass. After drying, the locusts were individually taken from the oven for immediate re-weighing to determine mass loss as a proxy for water content.

\subsection{Measurement of supercooling point and dissection}

Individual locusts ( $n=12$ per treatment; two acclimation regimes with two feeding states per gender) were weighed and placed into a polystyrene box $(100 \mathrm{~mm} \mathrm{H}, 250 \mathrm{~mm} \mathrm{~W}, 150 \mathrm{~mm} \mathrm{D}$ with a consistent wall thickness of $20 \mathrm{~mm}$ ) where flexible adhesive was used to fix the outstretched hind legs to the bottom surface to minimise movement. A thermocouple $(0.2 \mathrm{~mm}$ individual wire diameter) was then carefully inserted beneath the pronotum. The live wired locust was then immediately sealed in the box and placed into a $-20^{\circ} \mathrm{C}$ freezer. Locusts were measured individually with a second bare control wire using separate thermocouples connected to a multichannel datalogger (Datataker 500, BIOLAB Pty Ltd., Australia). The datalogger was connected to a computer and controlled by DeLogger data acquisition software (v. 4, Sven Holwell, BIOLAB Pty Ltd., Australia) using a $1 \mathrm{~s}$ recording frequency. The procedure resulted in a highly repeatable temperature decline curve that corresponded to an approximate $2{ }^{\circ} \mathrm{C} \mathrm{min}-1$ decrease from 20 to $0{ }^{\circ} \mathrm{C}$ that slowed to approximately $0.4{ }^{\circ} \mathrm{C} \mathrm{min}{ }^{-1}$ decrease sub-zero (Fig. 2). The freezing point of each locust was indicated by a sharp increase in temperature of $5-10{ }^{\circ} \mathrm{C}$ caused by the latent heat of crystallisation (Fig. 2). At least 10 min was allowed after the initial point of crystallisation to ensure the progression of freezing before the box was removed from the freezer for removal of the thermocouple and adhesive from the locust. Each locust was then dissected to remove the digestive tract by making a dorsal incision along the length the specimen to allow lateral opening. Fat deposits and tracheae connected to the tract were removed before weighing. The crop was then dissected from the tract and weighed individually. All experiments were conducted at a similar time of day that corresponded with the light period of either acclimation regime to avoid any diurnal rhythm effects (CloudsleyThompson, 1978).

\subsection{Low temperature exposure tolerance}

To quantify locust survival and determine any rapid cold hardening effect associated with a gradual decline in temperature, groups of fed individuals were cooled from $25^{\circ} \mathrm{C}$ to $-4,-6,-7$, $-8,-10$ and -12 at a rate of 0.1 and $0.5{ }^{\circ} \mathrm{C} \mathrm{min}^{-1}(n=50-67$ locusts per group per treatment). The locusts were contained in $15 \mathrm{~L}$ shallow plastic containers with an aluminium mesh lid and placed into a dark incubator capable of sub-zero temperatures that was programmed to decrease temperature at the required rate. Once the temperature had cooled to the treatment minimum, the locusts remained at this temperature for $3 \mathrm{~h}$. The $3 \mathrm{~h}$ time period was selected to approximate the typical period of minimum nightly temperature that persists after cooling until morning sunrise in the field (Australian Government Bureau of Meteorology, 2011). A control group was maintained at $25{ }^{\circ} \mathrm{C}$ for the entirety of each experimental period to evaluate any mortality associated with other factors. After exposure, the locusts were gradually returned to $25{ }^{\circ} \mathrm{C}$ over a 30 min period and survival was assessed $24 \mathrm{~h}$ later. Locusts that were able to right themselves, adopt a typ- 
Table 1

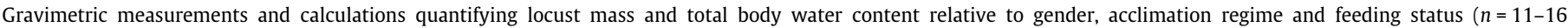
individuals per treatment group).

\begin{tabular}{|c|c|c|c|c|c|c|c|c|}
\hline & $\begin{array}{l}25 / 10^{\circ} \mathrm{C} \text { Fed } \\
\text { o }\end{array}$ & $\begin{array}{l}25 / 10^{\circ} \mathrm{C} \\
\text { Starved oै }\end{array}$ & $\begin{array}{l}25 / 10{ }^{\circ} \mathrm{C} \mathrm{Fed} \\
+\end{array}$ & $\begin{array}{l}25 / 10{ }^{\circ} \mathrm{C} \\
\text { Starved }+\end{array}$ & $\begin{array}{l}35 / 20{ }^{\circ} \mathrm{C} \text { Fed } \\
0^{\circ}\end{array}$ & $\begin{array}{l}35 / 20^{\circ} \mathrm{C} \\
\text { Starved }{ }_{0}{ }^{\circ}\end{array}$ & $\begin{array}{l}35 / 20^{\circ} \mathrm{C} \text { Fed } \\
+\end{array}$ & $\begin{array}{l}35 / 20^{\circ} \mathrm{C} \\
\text { Starved } \text { ㅇ }\end{array}$ \\
\hline Fresh mass $(\mathrm{g})$ & $1.141 \pm 0.195$ & $1.051 \pm 0.171$ & $2.113 \pm 0.305$ & $1.946 \pm 0.397$ & $1.173 \pm 0.189$ & $0.982 \pm 0.218$ & $2.097 \pm 0.285$ & $1.649 \pm 0.319$ \\
\hline Dry mass $(\mathrm{g})$ & $0.405 \pm 0.086$ & $0.408 \pm 0.064$ & $0.763 \pm 0.122$ & $0.705 \pm 0.165$ & $0.408 \pm 0.083$ & $0.388 \pm 0.075$ & $0.690 \pm 0.114$ & $0.626 \pm 0.093$ \\
\hline Total body water (g) & $0.736 \pm 0.112$ & $0.643 \pm 0.111$ & $1.349 \pm 0.197$ & $1.241 \pm 0.242$ & $0.764 \pm 0.117$ & $0.595 \pm 0.146$ & $1.407 \pm 0.192$ & $1.023 \pm 0.234$ \\
\hline Total body water content (\%) & $64.7 \pm 2.0$ & $61.1 \pm 2.0$ & $63.9 \pm 2.0$ & $64.0 \pm 2.7$ & $65.3 \pm 2.9$ & $60.2 \pm 2.2$ & $67.1 \pm 2.5$ & $61.7 \pm 2.7$ \\
\hline $\begin{array}{l}\text { Water per unit mass } \\
\qquad\left(\mathrm{g} \mathrm{H}_{2} \mathrm{O} \mathrm{g}^{-1} \text { dry mass }\right)\end{array}$ & $1.839 \pm 0.157$ & $1.576 \pm 0.137$ & $1.776 \pm 0.156$ & $1.789 \pm 0.204$ & $1.902 \pm 0.248$ & $1.522 \pm 0.144$ & $2.058 \pm 0.234$ & $1.622 \pm 0.189$ \\
\hline
\end{tabular}

ical standing posture and freely move and jump were regarded as alive.

\subsection{Data analysis}

Statistical differences between individual dependent continuous variables (i.e. supercooling points, total digestive tract mass and crop mass) and the categorical variables of gender, acclimation regime and feeding status were determined using ANOVA. Statistical correlation between mass, total body water content, total digestive tract mass, crop mass and supercooling point was determined by linear regression models. Survival data from the low temperature exposure tolerance experiments was analysed using probit regression for each treatment group to test for statistical differences between treatments and provide $\mathrm{Lt}_{50}$ and $\mathrm{Lt}_{90}$ values. Data analyses were performed using Statistix (v. 9, Analytical software, USA) and Minitab (v. 14, Minitab Inc., USA). Data are given as mean \pm s.d. throughout.

\section{Results}

\subsection{Locust mass and total body water content}

Total body water content ranged from $1.522 \pm 0.144$ to $2.058 \pm 0.234 \mathrm{~g}$ water $^{-1}$ dry mass (equating to $60.2 \pm 2.2 \%$ to $67.1 \pm 2.5 \%)$ and was significantly higher in females compared to males $\left(F_{(1,89)}=7.05, p=0.009\right)$ as well as fed compared to starved individuals $\left(F_{(1,89)}=43.42, p<0.001\right)$, but did not vary with acclimation regime $\left(F_{(1,89)}=1.40, p=0.240\right)$ (Table 1$)$.

\subsection{Dissected digestive tract and crop mass}

Total digestive tract mass and crop mass for each experimental treatment group (Table 2 ) was significantly higher in females compared to males $\left(F_{(1,93)}=96.93, p<0.001 ; F_{(1,93)}=34.10, p<0.001\right)$ as well as fed compared to starved individuals $\left(F_{(1,93)}=64.39\right.$, $\left.p<0.001 ; F_{(1,93)}=63.01, p<0.001\right)$, but did not vary with acclimation regime $\left(F_{(1,93)}=0.02, p=0.887 ; F_{(1,93)}=0.10, p=0.758\right)$. Significant interaction effects were observed for both digestive tract mass and crop mass relative to gender and feeding state $\left(F_{(1,93)}=8.41, p=0.005 ; F_{(1,93)}=5.26, p=0.024\right)$.

\subsection{Supercooling experiments}

The supercooling points across all experiments ranged from -6 to $-12.8^{\circ} \mathrm{C}$ (Table 2) and freezing was lethal. Supercooling points did not significantly vary with gender $\left(F_{(1,89)}=1.60, p=0.209\right.$ ), acclimation regime $\left(F_{(1,89)}=0.50, p=0.480\right)$ or feeding state $\left(F_{(1,89)}=0.80, p=0.375\right)$, but a significant interaction was observed for gender and feeding status $\left(F_{(1,89)}=7.01, p=0.010\right)$. Linear regression analyses showed significant negative correlations between the supercooling capacity of fed and starved females relative to increasing total digestive tract mass $\left(F_{(1,44)}=11.03, p=0.002\right)$ and crop mass $\left(F_{(1,44)}=9.88, p=0.003\right)$, but not fresh mass $\left(F_{(1,44)}=2.96, p=0.093\right)$. No significant correlations were observed for fed and starved males relative to the same variables.

\subsection{Low temperature exposure tolerance}

Exposure to a range of sub-zero temperatures for $3 \mathrm{~h}$ following gradual temperature decline showed $\geqslant 74 \%$ survival down to $-7{ }^{\circ} \mathrm{C}$ regardless of gender or cooling rate, but survival sharply declined to $\leqslant 37 \%$ when cooled to $-8{ }^{\circ} \mathrm{C}$ or lower (Fig. 3). Control mortality was very low $(\leqslant 3 \%)$ for all experimental treatments. Survival percentages were tightly clustered for each temperature treatment (range $\leqslant 6 \%$ ); except that survival was $10 \%$ and $24 \%$ higher for both males and females, respectively at a decline rate of 0.1 compared to $0.5{ }^{\circ} \mathrm{C} \mathrm{min}^{-1}$ to $-7{ }^{\circ} \mathrm{C}$ (range: $74-98 \%$ ), and that survival was $10 \%$ higher for males at a decline rate of 0.5 compared to $0.1^{\circ} \mathrm{C} \mathrm{min}{ }^{-1}$ to $-8{ }^{\circ} \mathrm{C}$. No significant differences were observed between probit regression models for each gender or cooling rate $(p>0.05)$; $\mathrm{Lt}_{50}$ and $\mathrm{Lt}_{90}$ ranged from -7.7 to -8.1 and -9.5 to $-10.0{ }^{\circ} \mathrm{C}$, respectively across all treatments (Table 3 ).

\section{Discussion}

Supercooling is an important adaptive response to surviving cold exposure in terrestrial arthropods that may experience cold conditions of varying severity and frequency at different life stages

Table 2

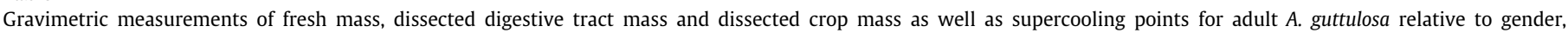
acclimation regime and feeding status ( $n=12$ individuals per treatment group).

\begin{tabular}{|c|c|c|c|c|c|c|c|c|}
\hline & $\begin{array}{l}25 / 10{ }^{\circ} \mathrm{C} \text { Fed } \\
0\end{array}$ & $\begin{array}{l}25 / 10^{\circ} \mathrm{C} \\
\text { Starved }{ }^{\star}\end{array}$ & $\begin{array}{l}25 / 10{ }^{\circ} \mathrm{C} \text { Fed } \\
\text { 우 }\end{array}$ & $\begin{array}{l}25 / 10^{\circ} \mathrm{C} \\
\text { Starved } \text { 우 }\end{array}$ & $\begin{array}{l}35 / 20{ }^{\circ} \mathrm{C} \text { Fed } \\
0\end{array}$ & $\begin{array}{l}35 / 20^{\circ} \mathrm{C} \\
\text { Starved }{ }^{\wedge}\end{array}$ & $\begin{array}{l}35 / 20^{\circ} \mathrm{C} \text { Fed } \\
\text { to }\end{array}$ & $\begin{array}{l}35 / 20^{\circ} \mathrm{C} \\
\text { Starved }{ }^{\circ}\end{array}$ \\
\hline Fresh mass (g) & $1.006 \pm 0.220$ & $1.024 \pm 0.172$ & $1.664 \pm 0.279$ & $1.715 \pm 0.392$ & $1.114 \pm 0.132$ & $1.060 \pm 0.214$ & $1.725 \pm 0.416$ & $1.724 \pm 0.307$ \\
\hline $\begin{array}{l}\text { Total digestive tract mass } \\
\quad(\mathrm{g})\end{array}$ & $0.138 \pm 0.047$ & $0.110 \pm 0.016$ & $0.292 \pm 0.055$ & $0.176 \pm 0.039$ & $0.173 \pm 0.039$ & $0.097 \pm 0.010$ & $0.280 \pm 0.106$ & $0.171 \pm 0.033$ \\
\hline Crop mass (g) & $0.061 \pm 0.035$ & $0.028 \pm 0.005$ & $0.097 \pm 0.033$ & $0.047 \pm 0.012$ & $0.056 \pm 0.022$ & $0.025 \pm 0.004$ & $0.112 \pm 0.059$ & $0.047 \pm 0.008$ \\
\hline Supercooling point $\left({ }^{\circ} \mathrm{C}\right)$ & $-10.4 \pm 1.2$ & $-9.3 \pm 1.5$ & $-8.8 \pm 1.6$ & $-10.5 \pm 1.2$ & $-9.9 \pm 1.8$ & $-9.8 \pm 1.8$ & $-8.8 \pm 1.6$ & $-9.5 \pm 1.5$ \\
\hline
\end{tabular}




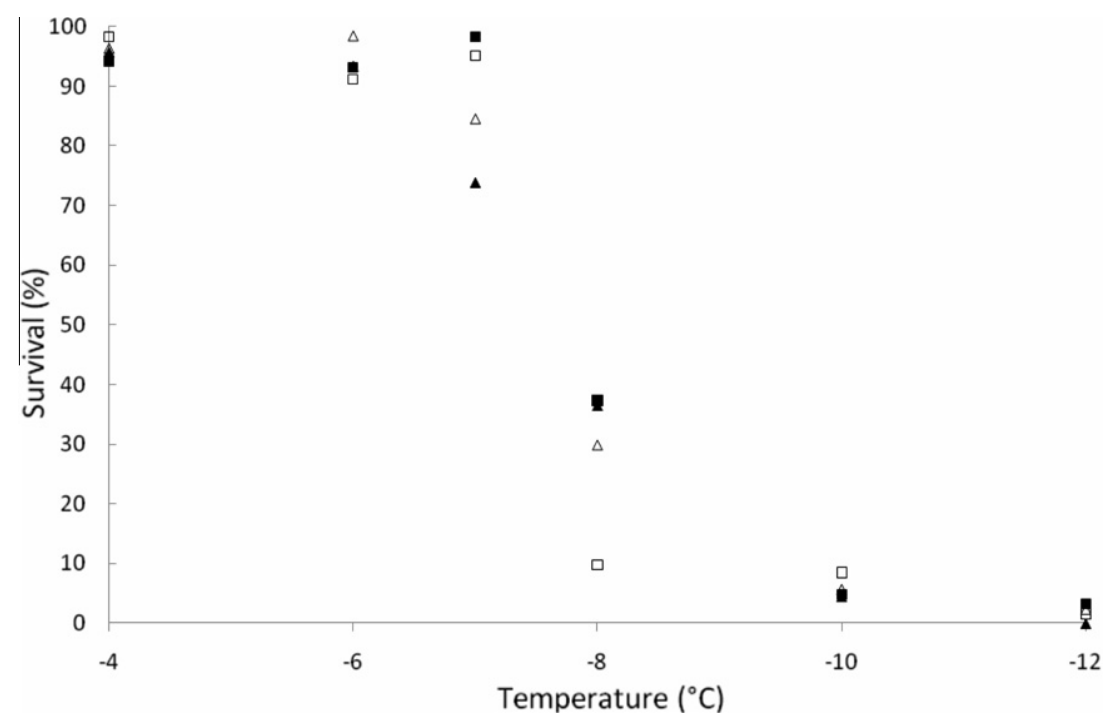

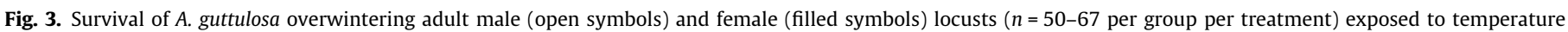
treatments from -4 to $-12{ }^{\circ} \mathrm{C}$ for $3 \mathrm{~h}$ following gradual temperature decline from $25^{\circ} \mathrm{C}$ at 0.1 (square symbols) and $0.5^{\circ} \mathrm{C}$ min ${ }^{-1}$ (triangle symbols).

Table 3

Lt50 and Lt90 values derived from probit regression analysis of survival data for overwintering male and female adult $A$. guttulosa locusts $(n=50-67$ per group per treatment) exposed to temperature treatments from -4 to $-12^{\circ} \mathrm{C}$ for $3 \mathrm{~h}$ following gradual temperature decline from $25^{\circ} \mathrm{C}$ at 0.1 and $0.5^{\circ} \mathrm{C} \mathrm{min}{ }^{-1}$.

\begin{tabular}{|c|c|c|c|c|}
\hline & $\delta^{7} 0.1^{\circ} \mathrm{C} \mathrm{min}-1$ & o $0.1^{\circ} \mathrm{C} \mathrm{min}^{-1}$ & o $0.5^{\circ} \mathrm{C} \mathrm{min}^{-1}$ & + $0.5^{\circ} \mathrm{C} \mathrm{min}^{-1}$ \\
\hline $\mathrm{Lt}_{50}\left({ }^{\circ} \mathrm{C}\right)$ & $-7.8 \pm 0.1$ & $-8.1 \pm 0.2$ & $-7.8 \pm 0.1$ & $-7.7 \pm 0.1$ \\
\hline $\mathrm{Lt}_{90}\left({ }^{\circ} \mathrm{C}\right)$ & $-9.6 \pm 0.2$ & $-10.0 \pm 0.2$ & $-9.6 \pm 0.2$ & $-9.5 \pm 0.2$ \\
\hline
\end{tabular}

and at different locations within a species distribution. The laboratory experiments reported here suggest that pre-reproductive adult $A$. guttulosa are not freeze tolerant, but supercool to temperatures lower than typical winter night minimums in the field. Importantly, death from freezing required that each individual remained in the freezer for at least $10 \mathrm{~min}$ after the initial point of crystallisation (see prolonged crystallisation transition duration in Fig. 2). In preliminary experiments, a small number of individuals survived cooling to the point of crystallisation presumably due to incomplete freezing following removal from the freezer within 1-2 min. The ability of some locusts to temporarily recover (i.e. these animals subsequently died within 7 days) from partial freezing reinforces the importance of the time component associated with progressive freezing of the body fluids, particularly in larger bodied species (Denlinger and Lee, 2010). Broadly, A. guttulosa showed a moderate supercooling ability compared to other terrestrial insects inhabiting semi-tropical and tropical environments (c.f. reviewed mean supercooling points of $-8.3 \pm 4.8$ to $-15.1 \pm 1.9{ }^{\circ} \mathrm{C}$ for freeze susceptible species in relevant sub-tropical and tropical habitats; Turnock and Fields, 2005). Among other locust species, A. guttulosa supercooling points were considerably lower than those for captive colony adult desert locusts, Schistocerca gregaria (means: -3.9 to $-4.8^{\circ} \mathrm{C}$ ) and adult African migratory locusts, Locusta migratoria (means: -4.1 to $-5.1^{\circ} \mathrm{C}$ ), despite similar fresh mass and body water contents (Cloudsley-Thompson, 1978). Within Australia, A. guttulosa supercooling points were slightly higher than nymphs of the Australian plague locust, Chortoicetes terminifera, which occupy a broader and more variable temperate distribution (supercooling point range -9.3 to $-14.6^{\circ} \mathrm{C}$ ) (Woodman, 2010).

Supercooling points for A. guttulosa were largely independent of fresh mass and body water content differences relative to gender, acclimation, and/or gut content in fed and starved individuals. The exception was an interaction effect of gender and feeding status whereby female locusts showed decreased supercooling capacity with increased food material in the digestive tract. Such an effect is not surprising given that supercooling ability has been commonly reported to decrease as body mass increases (e.g. Lee and Costanzo, 1998), but can depend on the amount, state and location of food in the digestive tract (Salt, 1961; CloudsleyThompson, 1978; Woodman, 2010). However, males showed no such relationship in the present study and the interaction effect is therefore most likely explained by the greater and more variable amount of food material that was consumed and contained within the digestive tract of the larger bodied females (Table 2). This explanation is supported by post-freezing dissections that showed smaller differences between digestive tract mass and crop mass for fed and starved males compared to females (Table 2). The food observed in the foregut of starved $A$. guttulosa of either gender likely resulted from anti-peristaltic muscular contractions causing anterior movement from the midgut (Cooper and He, 1994; Duve et al., 1999; Cooper and Beckage, 2010), and while the retained food material always appeared drier, this probably represents a priority survival function during the dry winter period when green grasses and forbs may be patchy and/or scarce (Farrow, 1977).

While supercooling points can be important measures of cold tolerance, quantifying the extent of pre-freeze mortality at higher and often more ecologically relevant temperatures can be more important to evaluating cold hardiness in terms of survival (e.g. Milonas and Savopoulou-Soultani, 2005). The present study shows that $A$. guttulosa is able to withstand cold exposure of similar progression and duration to diurnal thermal cycles in the field down to temperatures very close to the supercooling point. This contrasts with many insect species (especially from tropical regions) that face high mortality when exposed to low temperatures that may be below developmental or behavioural movement thresholds, but well above the supercooling point (Bale and Hayward, 2010; Hatherley et al., 2005). For example, in first-instar and adult peach-potato aphids (Myzus persicae), supercooling points of -26.6 and $-25^{\circ} \mathrm{C}$ were preceded by extensive pre-freezing mortality with $\mathrm{LT}_{50}$ temperatures of -8.1 and $-6.9^{\circ} \mathrm{C}$, respectively (Bale et al., 1988). The sudden decrease in A. guttulosa survival at -7 to $-8{ }^{\circ} \mathrm{C}$ (Fig. 3) is similar to that reported for tropical L. migratoria nymphs in China (Wang and Kang, 2003) as well as for C. terminif- 
era nymphs (Woodman, 2010). However, survival to $-7{ }^{\circ} \mathrm{C}$ was dependent on acclimation opportunity for rapid cold hardening in both L. migratoria and C. terminifera, and an empty gut for C. terminifera (Wang and Kang, 2003; Woodman, 2010). Rapid cold hardening describes a phenomenon previously described for a number of other insects whereby cold tolerance can be considerably increased relative to pre-exposure acclimation opportunity (e.g. Bahrndorff et al., 2009). However, the different laboratory cooling rates used in the present study failed to detect any such effect for A. guttulosa (noting that the possibility of a rapid cold hardening effect requiring cooling rates of $<0.1^{\circ} \mathrm{C} \mathrm{min}-1$ cannot be discounted).

Overwintering species often enhance their cold-hardiness in anticipation of winter conditions, however, this study found no difference in supercooling ability between locusts collected from the field during early winter and those collected at the same time and then acclimated to typical summer conditions. It is possible that the 'summer' acclimation period of 7-10 days and/or the lack of gradual change to the acclimation conditions was insufficient to down-regulate any enhanced supercooling capacity, but clear behavioural changes (e.g. greatly increased movement activity and feeding) were observed and dissections after acclimation confirmed the resumption of ovarian development (data not shown). While acclimation regimes similar to those used in the present study have shown no effect on supercooling ability in other studies (e.g. the land snail, Cornu aspersum; Ansart et al., 2008), it remains possible that a first instance of sub-zero, or near sub-zero, temperature may be required to trigger enhanced supercooling capacity largely irrespective of photoperiod or metabolic state (e.g. the carabid beetle, Pterostichus brevicornis; Baust, 1982). Alternatively, relatively large body size may restrain supercooling enhancement owing to a higher probability of spontaneous freezing in largerbodied insects (Lee and Denlinger, 2010). Furthermore, given that supercooling is unlikely to be required by many northern $\mathrm{A}$. guttulosa populations that do not migrate south, supercooling capacity may occur as a corollary of adaptation to other selection pressures (e.g. aridity, high temperature). Thus, cold hardiness in this species could be a manifestation of large body size as well as the inherent composition of the haemolymph (see Zachariassen, 1985), with limited or no apparent capacity to confer any rapid cold hardening benefits relative to acclimation opportunity. Future work could examine the regulation of water and ion movements to and from the gut (e.g. MacMillan and Sinclair, 2011) as well as identifying and quantifying cryoprotective compounds in the haemolymph.

The effects of sub-zero temperatures on overwintering locust populations is poorly understood in locust monitoring and forecasting in Australia (but see Woodman, 2010), and potentially represents an important component toward understanding field mortality rates and range limits. From this study, pre-freezing cold tolerance measures after different cooling rates down to a range of sub-zero temperatures as well as supercooling points indicate that exposure to cold and frosty nights would be unlikely to cause substantial mortality in the field, except perhaps for populations that migrate into exposed areas of increasing altitude. This conclusion may be further supported by observations that overwintering $A$. guttulosa commonly congregate in a reduced state of activity and roost in trees and other suitable vegetation (Farrow, 1977). In such a situation, microclimate may be affected by the density of trees in the area maintaining higher temperatures by reducing radiative cooling compared to more open areas (Davidson and Reid, 1985; Scowcroft and Jeffrey, 1999), physical buffering of frost by vegetation foliage (Curran et al., 2010), and vertical temperature gradients associated with radiative air temperature stratification (i.e. coldest temperatures are always nearest the ground) (Davidson and Reid, 1985). Therefore, while microclimatic measurements were not taken as part of this study, A. guttulosa may gain physical sheltering advantage from vegetation as well as being off the ground and loosely aggregated. Nonetheless, A. guttulosa is not only well adapted to warm and humid tropical and sub-tropical environments (Hunter et al., 2001; Hunter and Elder, 1999), but moderately able to avoid freezing if rapidly or gradually exposed to sub-zero temperatures.

\section{Acknowledgements}

Thanks to Australian Plague Locust Commission (APLC) field officers, Clare Mulcahy and Heather Brooks, for the collection of the locusts used in this study. Thanks also to Paul Cooper at the Australian National University for laboratory space and helpful comments throughout the work. Myron Zalucki at the University of Queensland and two anonymous reviewers provided helpful feedback on an earlier version of the manuscript. This research was financially supported by internal APLC funding.

\section{References}

Ansart, A., Aulne, P., Madec, L., Vernon, P., 2008. Influence of temperature acclimation and gut content on the supercooling ability of the land snail, Cornu aspersum. Comparative Biochemistry and Physiology Part A 150, 14-20.

Attapour, M., Moharramipour, S., 2009. Changes in cold hardiness, supercooling capacity, and major cryoprotectants in overwintering larvae of Chilo suppressalis (Lepidoptera: Pyralidae). Environmental Entomology 38, 260-265.

Bahrndorff, S., Loeschcke, V., Pertoldi, C., Beier, B., Holmstrup, M., 2009. The rapid cold hardening response of Collembola is influenced by thermal variability of the habitat. Functional Ecology 23, 340-347.

Bale, J.S., 2002. Insects and low temperatures: from molecular biology to distributions and abundance. Philosophical Transactions of the Royal Society of London B 357, 849-861.

Bale, J.S., Hayward, S.A., 2010. Insect overwintering in a changing climate. Journal of Experimental Biology 213, 980-994.

Bale, J.S., Harrington, R., Clough, M.S., 1988. Low temperature mortality of the peach-potato aphid Myzus persicae. Ecological Entomology 13, 121-129.

Baust, J.G., 1982. Environmental triggers to cold hardening. Comparative Biochemistry and Physiology Part A 73, 563-570.

Bureau of Meteorology, 2004. Australian Government Bureau of Meteorology, Melbourne, Viewed 1st December 2010. <http://www.bom.gov.au/climate/>.

Casimir, M., Edge, V.E., 1979. The development and impact of a control campaign against Austracris guttulosa in New South Wales. PANS 25, 223-236.

Chown, S.L., Nicholson, S.W., 2004. Insect Physiological Ecology: Mechanisms and Patterns. Oxford University Press, UK.

Chown, S.L., Gaston, K.J., Robinson, D., 2004. Macrophysiology: large-scale patterns in physiological traits and their ecological implications. Functional Ecology 18, 159-167.

Cloudsley-Thompson, J.L., 1978. Diurnal rhythms of supercooling in locusts. International Journal of Biometeorology 22, 112-115.

Cooper, P.D., Beckage, N.E., 2010. Effects of starvation and parasitism on foregut contraction in larval Manduca sexta. Journal of Insect Physiology 56, 1958-1965.

Cooper, P.D., He, P., 1994. Control of foregut contraction in the black field cricket, Teleogryllus commodus Walker (Gryllidae, Orthoptera). Journal of Insect Physiology 40, 475-481.

Curran, T.J., Reid, E.M., Skorik, C., 2010. Effects of severe frost on riparian rainforest restoration in the Australian wet tropics: foliage retention by species and the role of forest shelter. Restoration Ecology 18, 408-413.

Danks, H.V., 2007. The elements of seasonal adaptations in insects. Canadian Entomologist 139, 1-44.

Davidson, N.J., Reid, J.B., 1985. Frost as a factor influencing the growth and distribution of subalpine Eucalypts. Australian Journal of Botany 33, 657-667.

Denlinger, D.L., 1986. Dormancy in tropical insects. Annual Reviews of Entomology $31,239-264$.

Denlinger, D.L., Lee, R.E., 2010. Low Temperature Biology of Insects. Cambridge University Press, Cambridge, UK.

Duve, H., East, P.D., Thorpe, A., 1999. Regulation of lepidopteran foregut movement by allatostatins and allatotropin from the frontal ganglion. Journal of Comparative Neurology 413, 405-416.

Elder, R.J., 1989. Laboratory studies on the life history of Nomadacris guttulosa (Walker) (Orthoptera: Acrididae). Journal of the Australian Entomological Society 28, 247-253.

Elder, R.J., 1991. Laboratory studies on the environmental factors affecting sexual maturation in Nomadacris guttulosa (Walker) (Orthoptera: Acrididae). Journal of the Australian Entomological Society 30, 169-181.

Elder, R.J., 1995. Temporal incidence and sexual maturation of Austracris guttulosa (Walker) (Orthoptera: Acrididae) in Queensland, Australia. Journal of the Australian Entomological Society, 309-317.

Elnitsky, M.A., Hayward, S.A.L., Rinehart, J.P., Denlinger, D.L., Lee, R.E., 2008. Cryoprotective dehydration and the resistance to inoculative freezing in the 
390

J.D. Woodman/Journal of Insect Physiology 58 (2012) 384-390

Antarctic midge, Belgica antartica. Journal of Experimental Biology 211, 524530.

Farrow, R.A., 1977. Maturation and fecundity of the Spur-throated locust, Austracris guttulosa (Walker), in New South Wales during the 1974/75 plague. Journal of the Australian Entomological Society 16, 27-39.

Hadley, N.F., 1994. Water Relations of Terrestrial Arthropods. Academic Press Inc. San Diego, USA.

Hatherley, I.S., Hart, A.J., Tullett, A.G., Bale, J.S., 2005. Use of thermal data as a screen for the establishment potential of nonnative biological control agents in the UK. Biocontrol 50, 687-698.

Holmstrup, M., Sømme, L., 1998. Dehydration and cold hardiness in the Arctic Collembolan Onychiurus arcticus Tullberg 1876. Journal of Comparative Physiology Part B 168, 197-203.

Hunter, D.M., 1997. Vitellogenesis in Austracris guttulosa (Walker) (Orthoptera: Acrididae) in tropical Australia. Australian Journal of Entomology 36, 307-308.

Hunter, D.M., Elder, R.J., 1999. Rainfall sequences leading to population increases of Austracris guttulosa (Walker) (Orthoptera: Acrididae) in arid northeastern Australia. Australian Journal of Entomology 38, 204-218.

Hunter, D.M., Walker, P.W., Elder, R.J., 2001. Adaptations of locusts and grasshoppers to the low and variable rainfall of Australia. Journal of Orthopter Research 10, 347-351.

Kostal, V., Vambera, J., Bastl, J., 2004. On the nature of pre-freeze mortality in insects: water balance, ion homeostasis and energy change in the adults of Pyrrhocoris apterus. Journal of Experimental Biology 204, 1659-1666.

Krunic, M.D., Radovic, I.T., 1974. The effect of gut-content evacuation on the increase of cold-hardiness in Megachile rotundata. Entomologia Experimentalis et Applicata 17, 526-528.

Lee, R.E., Costanzo, J.P., 1998. Biological ice nucleation and ice distribution in coldhardy ectothermic animals. Annual Review of Physiology 60, 55-72.
Lee, R.E., Denlinger, D.L., 1991. Insects at Low Temperature. Chapman and Hall, New York.

MacMillan, H.A., Sinclair, B.J., 2011. The role of the gut in insect chilling injury: coldinduced disruption of osmoregulation in the fall field cricket, Gryllus pennsylvanicus. Journal of Experimental Biology 214, 726-734.

Milonas, P.G., Savopoulou-Soultani, M., 2005. Some attributes of cold hardiness of the gregarious ectoparasitoid Colpoclypeus florus (Hymenoptera: Eulophidae). Cryoletters 26, 395-399.

Salt, R.W., 1961. Principles of insect cold hardiness. Annual Review of Entomology 6, 55-74.

Scowcroft, P.G., Jeffrey, J., 1999. Potential significance of frost, topographic relief, and Acacia koa stands to restoration of mesic Hawaiian forests on abandoned rangeland. Forest Ecology and Management 114, 447-458.

Sinclair, B.J., Addo-Bediako, A., Shown, S.L., 2003. Climatic variability and the evolution of insect freeze tolerance. Biological Reviews 78, 181-195.

Turnock, W.J., Fields, P.G., 2005. Winter climates and cold hardiness in terrestrial insects. European Journal of Entomology 102, 561-576.

Wang, X., Kans, K., 2003. Rapid cold hardening in young hoppers of the migratory locust Locust migratoria L. (Orthoptera: Acridiidae). Cyroletters 24, 331-340.

Wilmer, P.G., 1982. Microclimate and environmental physiology of insects. Advances in Insect Physiology 16, 1-57.

Woodman, J.D., 2010. Cold tolerance of first-instar nymphs of the Australian plague locust, Chortoicetes terminifera. Journal of Insect Physiology 56, 376-379.

Worland, M.R., 2005. Factors that influence freezing in the sub-Antarctic springtail Tullbergia Antarctica. Journal of Insect Physiology 51, 881-894.

Zachariassen, K.E., 1985. Physiology of cold tolerance in insects. Physiological Reviews 65, 799-832. 